\title{
Transcriptome and physiological analysis of increase in drought stress tolerance by melatonin in tomato
}

Lu Yang ( $\nabla$ yanglu@ahnu.edu.cn )

Anhui Normal University https://orcid.org/0000-0003-0874-8841

Sijia Bu

Anhui Normal University

Shengxue Zhao

Anhui Normal University

Ning Wang

Anhui Normal University

Jiaxin Xiao

Anhui Normal University

Feng He

Anhui Normal University

Xiaoping Zhang

Anhui Normal University

Fengying Wan

Anhui Normal University

Lin Kang

Anhui Normal University

\section{Research Article}

Keywords: Tomato, PEG6000, drought, melatonin, photosynthesis, transcriptome

Posted Date: September 8th, 2021

DOI: https://doi.org/10.21203/rs.3.rs-853632/v1

License: () (1) This work is licensed under a Creative Commons Attribution 4.0 International License. Read Full License 


\section{Abstract}

Drought stress seriously affects tomato growth, yield and quality. Previous reports have pointed out that melatonin (MT) can alleviate drought stress damage to tomato. To better understand the possible physiological and molecular mechanisms, chlorophyll fluorescence parameters and leaf transcriptome profiles were analyzed in the "Micro Tom" tomato cultivar with or without melatonin irrigation under normal and drought conditions. Polyethylene glycol 6000 (PEG6000) simulated continuous drought treatment reduced plant height, but melatonin treatment improved plant growth rate. Physiological parameter measurements revealed that the droughtinduced decreases in maximum efficiency of photosystem II (PSII) photochemistry, the effective quantum yield of PSII, electron transfer rate, and photochemical quenching value caused by PEG6000 treatment were alleviated by melatonin treatment, which suggests a protective effect of melatonin on PSII. Comparative transcriptome analysis identified 447, 3982, 4526 and 3258 differentially expressed genes (DEGs) in the comparative groups plus-melatonin $v s$. minus-melatonin (no drought), drought $v s$. no drought (minus-melatonin), drought vs. no drought (melatonin) and plus-melatonin vs. minus-melatonin (drought), respectively. Furthermore, 101 DEGs were common to these four comparative groups. Gene Ontology and Kyoto Encyclopedia of Genes and Genomes analysis revealed that DEGs in the four comparative groups were involved in multiple metabolic processes and closely related to hormone signal transduction and transcription factors. These results provide new insights into a probable mechanism of the melatonin-induced protection of photosynthesis and enhancement of drought tolerance in tomato plants.

\section{Introduction}

With the deterioration of climatic and environmental conditions, global crop plant production is suffering from severe abiotic stresses, such as cold, drought and salt stress [1]. Drought is one of the most commonly encountered stress environments affecting crop yield and quality. High-temperature stress caused by global warming intensifies evaporation from soil horizontal, whereas altered precipitation patterns result in drought stress as a result of insufficient rainfall, causing reduced crop yield $[2,3,4]$. The loss of agricultural production caused by drought is greatest in China [5].

Tomato (Solanum lycopersicum L.) is an economically important crop, cultivated widely throughout the world. It is rich in nutrients and is an important model plant for studying the ripening of fleshy fruits [6]. Drought stress seriously affects the growth and development of tomato, resulting in large-scale yield reductions [7, 8]. Previous studies have shown that drought stress can change the physiological and biochemical characteristics of tomato leaves, causes damage to the photosynthetic system, reduces plant growth rate and dry matter accumulation, and affects flowering, fruit setting and ripening $[9,10,11]$.

Polyethylene glycol 6000 (PEG6000) is a hydrophilic macromolecule with a molecular mass of $6000 \mathrm{Da}$. When PEG6000 is applied in the irrigation water, it is difficult for plant roots to absorb water from the soil because the water potential of the PEG6000 solution is low. Therefore, PEG6000 is often used as an agent to simulate drought experimentally [12]. Melatonin (MT), also known as N-acetyl-5methoxytryptamine, belongs to the indole tryptamines. It can promote vegetative growth of horticultural plants, inhibit reproductive growth, regulate photoperiod, regulate root development, delay leaf senescence, and affect fruit ripening and storage [13]. Also, many studies have shown that melatonin is an active antioxidant, involved in the regulation of abiotic and biotic stress tolerance of horticultural crops. For example, under drought stress, exogenous melatonin can activate the antioxidant system of apple, removing excess reactive oxygen species (ROS), improving the efficiency of light energy conversion and carbon assimilation in leaves, and then alleviating drought symptoms [14]. The photosynthetic rate and drought tolerance of cucumber seedlings grown under osmotic stress were significantly increased by exogenous melatonin treatment [15]. Melatonin treatment can improve thermotolerance in several plant species such as rice, Arabidopsis, tomato, and tall fescue [16-19]. In maize, exogenous melatonin application enhanced salt stress tolerance by improving antioxidant and photosynthetic capacity, and melatonin can also exert a protective role against drought stress $[20,21]$. Additionally, damage caused by cold stress can be alleviated by melatonin treatment of Arabidopsis thaliana and cucumber $[22,23]$. For abiotic stress, melatonin can induce disease resistance to the fungal pathogen Botrytis cinerea in tomato fruit by activating the jasmonic acid signaling pathway [24]. Exogenous application of melatonin can also contribute to pathogen resistance in apple (to the fungal pathogen Diplocarpon mali), Lupinus albus (Penicillium spp.) and Arabidopsis (to the bacterial pathogen Pseudomonas syringae pv. tomato (Pst) DC3000) [25, 26, 27].

In tomato, melatonin application can affect plant growth and fruit ripening $[28,29]$. Melatonin treatment also mitigated chilling-induced oxidative stress and photosynthetic inhibition, and alleviated heat-induced damage to tomato seedlings by balancing redox homeostasis and modulating polyamine and nitric oxide biosynthesis [30]. Overexpression of the melatonin synthesis-related tomato gene SICOMT1 improved the tolerance of tomato to salt stress [31]. With respect to drought-stressed plants, studies showed that

Page 2/18 
melatonin treatment enhanced the photosynthetic performance and antioxidant capacity of tomato seedlings [32]. Melatonin can improve plant stress tolerance by inhibiting ROS production in chloroplasts and by regulating photosynthetic electron transport and D1 protein synthesis [32]. From the cytological point of view, previous studies had shown that, in tomato plants, exogenous melatonin application improved tolerance to water deficit by promoting cuticle formation [33]. A recent study showed that exogenous melatonin application could help alleviate deleterious effects of PEG (simulating drought) by enhancing antioxidant mediated defense and by increasing the concentrations of some phenolics [34]. Recently, a study highlighted the positive effect of melatonin in open-field droughted tomato plants by enhancing the quantity and quality of strategic crops [35].

Despite these multiple physiological and biochemical effects of melatonin, changes in gene expression levels in tomato in response to melatonin irrigation in the presence of PEG6000 have not yet been elucidated. In the present study, RNA-sequencing (RNA-Seq) technology was used to examine the effect of the response to melatonin irrigation in normal and drought-stressed plants. Combined with the analysis of chloroplast fluorescence parameters, such as maximum efficiency of photosystem II (PSII) photochemistry (Fv/Fm), the effective quantum yield of PSII (Fv'/Fm'), electron transfer rate (ETR), photochemical quenching (qP), non-photochemical quenching coefficient ( $q N$ ) and stern-volmer nonphotochemical quenching (NPQ), the analysis of plant phenotype and differentially expressed genes (DEGs) will lay the foundation for further explanation of the role of melatonin in inducing drought tolerance in tomato.

\section{Materials And Methods Plant materials and treatments}

Solanum lycopersicum L. cv. Micro-Tom was selected as the wild type (WT). Tomato plants were grown in a greenhouse with standard conditions ( $18 \mathrm{~h}$ light $/ 6 \mathrm{~h}$ dark, $25^{\circ} \mathrm{C}$ day $/ 18^{\circ} \mathrm{C}$ night, and $60 \%$ relative humidity) and watered daily. For drought stress experiment, one month old tomato plants with the same growth potential were selected. The plant was cultivated on imported peat with weak acidity and $\mathrm{pH}$ 5.5. The experiment was divided into control group and drought experimental group. Three melatonin treatment concentrations $(0 \mu \mathrm{moL} / \mathrm{L} \otimes 10 \mu \mathrm{moL} / \mathrm{L} \otimes 50 \mu \mathrm{moL} / \mathrm{L})$ were set in each group. Root irrigation was used and the treatment time and position were fixed. Three tomato plants were selected as biological repeats for each concentration and following treatment was then carried out: (1) The tomato seedlings in the experimental group were treated with $50 \mathrm{~mL}$ PEG6000 solution of $100 \mathrm{mmol} / \mathrm{L}$, and the control group were treated with $50 \mathrm{~mL} \mathrm{ddH_{2 }}$; (2) The next day, the tomato seedlings of the experimental group and the control group were treated with 50 $\mathrm{mL}$ melatonin solution of gradient concentration $(0 \mu \mathrm{mol} / \mathrm{L}, 10 \mu \mathrm{mol} / \mathrm{L}, 50 \mu \mathrm{mol} / \mathrm{L})$ respectively. (3) PEG6000 and melatonin solution were performed alternately and two days treatment was a cycle, the treatment was finished after eight cycles (16 days).

\section{Chlorophyll fluorescence parameters}

A portable fluorometer was used at room temperature to measure chlorophyll fluorescence parameters of fully expanded tomato leaves, at least three plants were used in each treatment. After full dark adapted within two hours, all the electronic gates were in the open state, the minimum fluorescence yield at the dark-adapted state (F0) was recorded. Then a saturation pulse of $3000 \mu \mathrm{mol}$ (photon) $\mathrm{m}^{-2} \mathrm{~s}^{-1}$ for $3 \mathrm{~s}$ was given, at this time, all the electronic gates convert the energy used for photosynthesis into fluorescence and heat, and the maximal fluorescence yield at the dark-adapted state ( $F m)$ was recorded. After that, the maximal (Fm') and minimum (F0') fluorescence yield at the light adapted state, steady state (Fs) fluorescence yield at the light adapted state were measured with tomato leaves treated with an active light of $1000 \mu \mathrm{mol}$ (photon) $\cdot \mathrm{m}^{-2} \mathrm{~s}^{-1}$. Fv represented variable fluorescence at the dark-adapted state. Maximum efficiency of PSII photochemistry was calculated as Fv/Fm, where Fv = Fm - F0; the effective quantum yield of PSII was calculated as Fv'/Fm', where $\mathrm{Fv}^{\prime}=\mathrm{Fm}^{\prime}-\mathrm{FO} 0^{\prime}$; and $\left.\mathrm{qP}=\left(\mathrm{Fm}^{\prime}-\mathrm{Fs}\right) /\left(\mathrm{Fm}^{\prime}-\mathrm{FO}\right)^{\prime}\right)$ were determined in the light adapted state. And also, Stern-Volmer nonphotochemical quenching $\left(N P Q, N P Q=\left(F m-F m^{\prime}\right) / F m^{\prime}\right)$ together with electron transfer rate $(E T R, E T R=\Phi P S \otimes \times i \times a$ $\times f$, in which $i$, a and $f$ represents intensity of incident light, absorption ratio of incident light, and estimated value of F-energy distribution proportion, respectively) were also calculated and recorded [36, 37, 38].

\section{Preparation of RNASeq libraries and sequencing of tomato}

After treatment, leaves of tomato plant with and without melatonin irrigation under normal and PEG6000 treatment conditions were collected. For each group, two biological replicates were carried out, total RNA was extracted and then treated with RNase-free DNase I (Thermo, USA) to remove contaminating genomic DNA. cDNA libraries were then constructed for sequencing on the DNBSEQ platform (BGI, China). Clean data were obtained by removing reads containing adapters and low-quality reads from the raw data. All subsequent analyses were based on clean, high-quality data. The average blast ratio of sample to genome was $97.52 \%$ and the average matching rate was $86.56 \%$. A total of 27738 genes were detected successfully. 


\section{Transcriptome analyses of tomato leaves}

Given that the tomato genome data has been published, the reference genome version is IATG 4.0_release. After grouping multiple samples of biological duplication into a group, the types of pairwise comparisons were as follows: $10 \mu \mathrm{M}$ melatonin irrigation group compared to $0 \mu \mathrm{M}$ melatonin irrigation group, both groups performed without PEG6000 treatment (CM10-vs-CM0); $10 \mu \mathrm{M}$ melatonin irrigation group compared to $0 \mu \mathrm{M}$ melatonin irrigation group, both groups performed with $100 \mathrm{mM}$ PEG6000 treatment (TM10-vsTM0); 100 mM PEG6000 treatment group compared to 0 mM PEG6000 treatment group, both groups performed without melatonin irrigation (TM0-vs-CM0); $100 \mathrm{mM} \mathrm{PEG6000} \mathrm{treatment} \mathrm{group} \mathrm{compared} \mathrm{to} 0 \mathrm{mM} \mathrm{PEG6000} \mathrm{treatment} \mathrm{group,} \mathrm{both} \mathrm{groups} \mathrm{performed} \mathrm{with}$ $10 \mu \mathrm{M}$ melatonin irrigation (TM10-vs-CM10). For difference analysis of gene expression between two groups, the method of DEG-seq was used based on Poisson distribution [39]. In order to improve the accuracy of differentially expressed genes (DEGs), genes with more than two times of difference and Q-value $\leq 0.001$ were defined as the significantly differentially expressed genes. For DEGs in multiple comparison groups, Venn diagrams was used for displaying. For GO enrichment, the DEGs were classified into several functional groups according to $\mathrm{GO}$ annotation results and official classification method. At the same time, the Phyper function in $\mathrm{R}$ software was used for enrichment analysis, then $p$ value was calculated and FDR correction was performed. When the corrected $p$ value (Qvalue) $\leq 0.05$, it was considered that the GO function was significantly enriched. According to the KEGG pathway annotation classification, the Phyper function in R software was used for enrichment analysis, $p$ value was calculated and then corrected by FDR. Similarly, the function with Qvalue $\leq 0.05$ is regarded as significant enrichment.

\section{Verification of DEGs identified from RNA-Seq by qPCR}

Fourteen randomly selected DEGs originated from RNA-Seq data were verified by qRT-PCR. Firstly, total RNAs were extracted using Plant RNA Extraction Kit following the protocol provided by the manufacturer (Tiangen, China). About $2 \mu \mathrm{g}$ of total RNA from each sample was used for first-strand cDNA synthesis (NovoScript, China). For quantitative real-time PCR (qPCR), Slactin was used as internal control and the reaction was performed with SuperReal PreMix Plus (SYBR Green) (Tiangen, China). Gene-specific primers were designed with the software of DNAMAN8 and $20 \mu \mathrm{L}$ reaction system contained $1.0 \mu \mathrm{L}$ of cDNA, $1.2 \mu \mathrm{L}$ of primers, $10 \mu \mathrm{L}$ of $2 \times$ SuperReal PreMix Plus, and $7.8 \mu \mathrm{L}$ of distilled water. The procedures of PCR amplification consisted of an initial incubation at $95^{\circ} \mathrm{C}$ for $15 \mathrm{~min}$, followed by 40 cycles of $95^{\circ} \mathrm{C}$ for $10 \mathrm{~s}$ and $60^{\circ} \mathrm{C}$ for $30 \mathrm{~s}$ with Bio-Rad CFX connect (Bio-Rad) and melting curve analysis was performed ranging $60-95^{\circ} \mathrm{C}$. Each sample was amplified in triplicate and the cycle threshold $(\mathrm{Ct}) 2^{-\Delta(\Delta \mathrm{Ct})}$ method was adopted for relative quantification of specific mRNA levels. All primers for qPCR are listed in Table S13.

\section{Results}

\section{Plant growth}

Here, the PEG6000-treated group and the non-PEG6000-treated group were described as the experimental group (TM) and the control group (CM), respectively. As shown in Fig. 1A, the height of plants in the experimental group was shorter than that of the control group, regardless of whether melatonin $(0,10,50 \mu \mathrm{mol} / \mathrm{L})$ was applied or not. Interestingly, in the experimental group, compared with the experimental plants grown without melatonin (TM0), $10 \mu \mathrm{mol} / \mathrm{L}$ melatonin (TM10) alleviated leaf wilting. However, the effect of 50 $\mu \mathrm{mol} / \mathrm{L}$ melatonin (TM50) was not obvious (Fig. 1A). The height of plants in the experimental groups (TM0, TM10, TM50) were clearly lower than that of the control group (CM0, CM10, CM50), whether measured on the fifth or seventh days. During the processing cycle from day 5 to day 7 , in the control group, the percentage increase in height of CM0, CM10 and CM50 plants was $18.27 \%, 19.87 \%$ and $25.00 \%$, respectively; and in experimental group, the corresponding increases of TM0, TM10 and TM50 were $1.20 \%, 10.13 \%$ and $7.76 \%$, respectively. In other word, in either the control or experimental groups, plant height increased ratio was greater after applying melatonin solution. Interestingly, in the experimental group, the percentage plant height increase was greatest with the application of $10 \mu \mathrm{mol} / \mathrm{L}$ melatonin, compared with 0 or $50 \mu \mathrm{mol} / \mathrm{L}$ melatonin (Fig. 1B).

\section{Photosynthetic performance}

The Fv/Fm, Fv'/Fm', ETR, qP, qN and NPQ were measured and compared between the experimental and control groups. Without melatonin treatment, the Fv/Fm, Fv'/Fm', ETR, and qP of tomato plants decreased in the stressed plants of the experimental group when compared with the non-stressed plants of the control group, which indicated that PSII was damaged. After melatonin irrigation, irrespective of the concentration (10 or $50 \mu \mathrm{mol} / \mathrm{L}$ ), the decrease in Fv/Fm, Fv'/Fm', ETR, and qP value caused by stimulated drought stress in the experimental group was greatly diminished (Fig. 2A-D). The effect of melatonin on qN was not significant, which 
suggested that melatonin had no obvious effect on the heat loss of plants to tolerate drought stress (Fig. 2E). Melatonin (10 $\mu \mathrm{mol} / \mathrm{L})$ increased NPQ, whereas the effect was not significant with $50 \mu \mathrm{mol} / \mathrm{L}$ melatonin treatment (Fig. 2F).

\section{Identification of differentially expressed genes}

Transcriptome analysis of tomato leaves treated with $0 \mu \mathrm{mol} / \mathrm{L}(\mathrm{CM} 0)$ or $10 \mu \mathrm{mol} / \mathrm{L}$ (CM10) melatonin in the control (non-stressed) group and $0 \mu \mathrm{mol} / \mathrm{L}(\mathrm{TM} 0)$ or $10 \mu \mathrm{mol} / \mathrm{L}$ (TM10) melatonin in the experimental (drought-stressed) group was performed. The results revealed that, without exposure to drought, a total of $447 \mathrm{DEGs}$ were found in tomato leaves treated with $10 \mu \mathrm{mol} / \mathrm{L}$ (CM10) melatonin, when compared with those treated with $0 \mu \mathrm{mol} / \mathrm{L}(\mathrm{CM} 0)$ melatonin, including 174 up-regulated genes and 273 down-regulated genes (CM10-vs-CM0) (Table S1, Fig. 3A). In the presence of drought stress, however, a total of 3258 DEGs were found in tomato leaves treated with $10 \mu \mathrm{mol} / \mathrm{L}(\mathrm{TM} 10)$ melatonin, when compared with those treated with $0 \mu \mathrm{mol} / \mathrm{L}$ (TM0) melatonin, namely 819 up-regulated genes and 2439 down-regulated genes (TM10-vs-TM0) (Table S2, Fig. 3A). In the absence of melatonin, a total of 3982 DEGs were identified in drought-stressed plants, namely 2734 up-regulated genes and 1248 down-regulated genes (TM0-vs-CM0) (Table S3, Fig. 3A); after treatment with $10 \mu \mathrm{mol} / \mathrm{L}$ melatonin, a total of $4526 \mathrm{DEGs}$ were identified in drought-stressed plants, namely 2337 upregulated genes and 2189 down-regulated genes (TM10-vs-CM10) (Table S4, Fig. 3A).

Therefore, the largest number of DEGs between TM10 and CM10 (TM10-vs-CM10), whereas the smallest number occurred between CM10 and CM0 (CM10-vs-CM0). Furthermore, a Venn diagram showed that there were 101 DEGs in common among the four groups, with the TM10-vs-TM0, TM0-vs-CM0, TM10-vs-CM10 groups sharing 755 DEGs; the TM10-vs-TM0, CM10-vs-CM0, TM10-vs-CM10 groups sharing 128 DEGs; the TM0-vs-CM0, CM10-vs-CM0, TM10-vs-CM10 groups sharing 160 DEGs; the TM10-vs-TM0, TM0-vs-CM0, CM10-vs-CM0 groups sharing 139 DEGs. The comparison between pairs of groups showed that the TM0-vs-CM0 and TM10-vs-CM10 groups had 2362 DEGs in common; the TM10-vs-TM0 and TM0-vs-CM0 groups had 1566 DEGs in common; the TM10-vs-TM0 and TM10-vs-CM10 groups had 1679 DEGs in common; the CM10-vs-CM0 and TM10-vs-CM10 groups had 249 DEGs in common; the TM0vs-CM0 and CM10-vs-CM0 groups had 239 DEGs in common; and the TM10-vs-TM0 and CM10-vs-CM0 groups had 214 DEGs in common (Fig. 3B).

\section{Gene Ontology (GO) analyses of DEGs}

Gene Ontology (GO) is a major bioinformatics initiative to unify the representation of gene and gene product attributes across all species, covering three domains, namely cellular component (CC), molecular function (MF) and biological process (BP). The results of this study showed that the DEGs in the CM10-vs-CM0 group were classified into 37 functional terms, namely 16 terms in BP, 11 terms in $\mathrm{CC}$, and ten terms in MF. Within BP, cellular processes and metabolic processes were predominant. Biological regulation and response to stimulus and localization had the most annotations, while cell proliferation, cell killing, detoxification and carbon utilization had the fewest. Within the CC domain, cell, membrane, membrane part and organelle represented the majority of DEGs in this category, whereas the fewest classifications were membrane-enclosed lumen, cell part, cell junction and symplast. Similarly, for $\mathrm{MF}$, binding and catalytic activity were the most abundantly assigned terms, followed by transcription regulator activity and transporter activity, whereas the terms with the fewest classification was nutrient reservoir activity (Fig. 4A).

The total DEGs between TMO-vs-CMO were classified into 46 functional terms, namely 20 terms in BP, 15 terms in CC, and 11 terms in MF. Within BP, cellular process and metabolic process were the dominant subcategories followed by biological regulation, response to stimulus and localization, whereas carbon utilization, cell killing, cell proliferation, detoxification, biological adhesion and rhythmic process had the fewest subcategories. Within the CC domain, cell, membrane, membrane part and organelle represented the majority of terms in this category, whereas the fewest classifications were in the virion part, virion, nucleoid. Similarly, for MF, binding and catalytic activity were the most abundantly assigned terms, followed by transcription regulator activity and transporter activity, whereas the terms with the fewest assignments was molecular carrier activity (Fig. 4B).

The DEGs of TM10-vs-CM10 were classified into 47 functional terms, namely 20 terms in BP, 15 terms in CC, and 12 terms in MF. Within the BP domain, cellular process and metabolic process were the dominant terms, followed by biological regulation and response to stimulus, whereas carbon utilization, cell killing, cell proliferation, biological adhesion and rhythmic process had the fewest terms. With the CC domain, cell, membrane, membrane part and organelle represented the majority of the DEGs, but few genes were assigned to the subcategories of supramolecular complex, virion part, virion and nucleoid. Similarly, for the MF domain, binding and catalytic activity were the most abundantly assigned DEGs, whereas the terms with the fewest assignments were molecular carrier activity and protein tag (Fig. 4C). 
The DEGs of TM10-vs-TM0 were classified into 42 functional terms, namely 17 terms in BP, 14 terms in CC, and 11 terms in MF. Within the BP domain, cellular process and metabolic process were the dominant subcategories, followed by biological regulation, response to stimulus and localization, whereas immune system process, cell proliferation, detoxification and biological adhesion were the least abundantly assigned terms. Within the $\mathrm{CC}$ domain, cell, membrane, membrane part and organelle represented the majority of the DEGs, few genes were assigned to the categories of supramolecular complex, virion part and virion. Similarly, for the MF domain, binding and catalytic activity were the most abundantly assigned DEGs, followed by transcription regulator activity and transporter activity, whereas the least abundantly assigned DEGs were nutrient reservoir activity and molecular carrier activity (Fig. 4D).

\section{Kyoto Encyclopedia of Genes and Genomes (KEGG) analyses of DEGs}

Kyoto Encyclopedia of Genes and Genomes (KEGG) is a large-scale database for systematic analysis of gene function and association between genomic information and functional information. The pathways of cellular processes (CP), environmental information processing (EIP), genetic information processing (GIP), human diseases (HD), metabolism (M) and organizational systems (O) in the KEGG database were used for DEG analysis in the current study (Fig. 5).

In general, the highest number of DEGs among the four groups were all involved with metabolism, according to KEGG. More specifically, in the CM10-vs-CM0 comparison, the greatest number of DEGs was involved in global and overview maps, with the smallest number of DEGs being involved in membrane transport, replication and repair and endocrine and metabolic diseases (Fig. 5A). In the TMO-vs-CMO group comparison, the greatest number of DEGs was involved in global and overview maps and the smallest number of DEGs was involved in membrane transport and endocrine and metabolic diseases (Fig. 5B). In the comparison of TM10-vs-CM10, the greatest number of DEGs was involved in global and overview maps, whereas the smallest number of DEGs was involved in nucleotide metabolism and endocrine and metabolic diseases (Fig. 5C). In the comparison of TM10-vs-TM0, the greatest number of DEGs was involved in global and overview maps and the smallest number of DEGs was involved in membrane transport, endocrine and metabolic diseases, and nucleotide metabolism (Fig. 5D).

\section{Classification of DEGs according to hormones and transcription factors}

The DEGs in these four groups were then classified according to hormones and transcription factors. Based on hormone classification, there were 13 ethylene (Eth)-related genes, six auxin (IAA)-related genes, three abscisic acid (ABA)-related genes, two cytokinin (CK)related genes, one gibberellin (GA)-related gene and two salicylic acid (SA)-related genes out of 447 DEGs in the group CM10-vs-CM0, of which Solyc05g024260.3 was involved in both the ABA and SA metabolic pathways (Table S5). Out of the 3982 DEGs in the TM0vs-CM0 group, 61 Eth-related genes, 41 IAA-related genes, 27 ABA-related genes, 25 CK-related genes, 35 GA-related genes and 16 SArelated genes were obtained (Table S6). Out of the 4526 DEGs in the group TM10-vs-CM10, 53 Eth-related genes, 54 IAA-related genes, 37 ABA-related genes, 29 CK-related genes, 28 GA-related genes and 19 SA-related genes were identified (Table S7). Out of the 3258 DEGs in the TM10-vs-TM0 group, 56 Eth-related genes, 46 IAA-related genes, 17 ABA-related genes, 12 CK-related genes, 19 GA-related genes and eight SA-related genes were identified (Table S8). Among the 101 DEGs common to the above four groups, ten were related to hormones and five were related to ethylene; more detailed information can be found in Table 1.

The DEGs were then classified on the basis of transcription factors. Out of the DEGs from the group of CM10-vs-CM0, nine MYB-related genes, two bHLH-related genes, one NAC-related gene, five MADS-related genes, four WRKY-related genes, 13 AP2-related genes, four $\mathrm{C} 2 \mathrm{H} 2$-related genes and one bZIP-related gene were identified (Table S9). Among the DEGs from the comparison of TM0-vs-CM0, 54 MYB-related genes, 31 bHLH-related genes, 34 NAC-related genes, 11 MADS-related genes, eight HSF-related genes, 15 WRKY-related genes, 57 AP2-related genes, $17 \mathrm{C} 2 \mathrm{H} 2$-related genes and four bZIP-related genes were identified (Table S10). Out of the DEGs from the TM10-vs-CM10 comparison group, 55 MYB-related genes, 51 bHLH-related genes, 36 NAC-related genes, 14 MADS-related genes, nine HSF-related genes, 17 WRKY-related genes, 48 AP2-related genes, $16 \mathrm{C} 2 \mathrm{H} 2$-related genes and ten bZIP-related genes were identified (Table S11). Out of the DEGs from the TM10-vs-TM0 comparison group, 42 MYB-related genes, 45 bHLH-related genes, 32 NAC-related genes, 18- MADS related genes, four HSF-related genes, 21 WRKY-related genes, 61 AP2-related genes, eight C2H2-related genes and eight bZIP-related genes were identified (Table S12). In general, 11 DEGs (one MYB, one bHLH, five AP2, three C2H2 and one bZIP gene) encoded transcription factors common to the four groups (Table 2). 
Table 1

Hormone related DEGs shared by four groups

\begin{tabular}{|c|c|c|c|c|c|c|}
\hline Gene ID & hormone & $\log 2(\mathrm{CM} 10 / \mathrm{CM} 0)$ & $\log 2(\mathrm{TMO} / \mathrm{CM} 0)$ & $\log 2(\mathrm{TM} 10 / \mathrm{CM} 10)$ & $\log 2(\mathrm{TM} 10 / \mathrm{TM} 0)$ & Description \\
\hline Solyc06g035700.1 & Eth & -2.569973739 & 5.726104117 & 2.233921858 & -6.062155998 & ERF025-like \\
\hline Solyc10g050970.1 & Eth & -1.304257551 & 4.642995359 & 1.155919346 & -4.791333565 & ERF109-like \\
\hline Solyc01g095140.4 & Eth & -1.031503824 & 5.697679565 & 2.422914962 & -4.306268427 & ER5 protein \\
\hline Solyc04g071770.3 & Eth & 1.046931654 & 4.148131752 & 1.415439268 & -1.685760831 & $\begin{array}{l}\text { ERF ABR1- } \\
\text { like }\end{array}$ \\
\hline Solyc01g108240.3 & Eth & -2.985011238 & 6.732941547 & 4.101471562 & -5.616481223 & ERF109 \\
\hline Solyc09g008175.1 & IAA & -1.698707053 & -1.394928001 & -2.072899344 & -2.376678397 & SAUR71 \\
\hline Solyc11g069093.1 & IAA & -1.463058535 & -2.139471002 & -3.821360577 & -3.144948111 & $\begin{array}{l}\text { auxin- } \\
\text { induced } \\
\text { protein X15 }\end{array}$ \\
\hline Solyc05g024260.3 & $\mathrm{ABA}$ & 1.257845286 & 8.849939626 & 8.861256981 & 1.26916264 & $\begin{array}{l}\text { bidirectional } \\
\text { sugar } \\
\text { transporter } \\
\text { N3 }\end{array}$ \\
\hline Solyc11g072310.2 & $\mathrm{GA}$ & 2.117350479 & 3.76016864 & 2.883632627 & 1.240814466 & $\begin{array}{l}\text { gibberellin } \\
20 \text { oxidase } \\
\text { 1-like }\end{array}$ \\
\hline Solyc05g024260.3 & SA & 1.257845286 & 8.849939626 & 8.861256981 & 1.26916264 & $\begin{array}{l}\text { bidirectional } \\
\text { sugar } \\
\text { transporter } \\
\text { N3 }\end{array}$ \\
\hline
\end{tabular}

Table 2

Transcription factor related DEGs shared by four groups

\begin{tabular}{|c|c|c|c|c|c|c|}
\hline Gene ID & TFs & $\log 2(\mathrm{CM} 10 / \mathrm{CM} 0)$ & $\log 2(\mathrm{TMO} / \mathrm{CMO})$ & $\log 2(\mathrm{TM} 10 / \mathrm{CM} 10)$ & $\log 2(T M 10 / T M 0)$ & Description \\
\hline Solyc02g085145.1 & MYB & -1.739254824 & -2.420415605 & -7.389045087 & -6.707884305 & $\begin{array}{l}\text { protein } \\
\text { RADIALIS-like } 5\end{array}$ \\
\hline Solyc03g114230.2 & $\mathrm{bHLH}$ & -4.306939333 & 1.836246718 & 4.233921858 & -1.909264193 & bHLH27-like \\
\hline Solyc06g035700.1 & AP2 & -2.569973739 & 5.726104117 & 2.233921858 & -6.062155998 & ERF025-like \\
\hline Solyc10g050970.1 & AP2 & -1.304257551 & 4.642995359 & 1.155919346 & -4.791333565 & ERF109-like \\
\hline Solyc03g124110.2 & AP2 & -2.132834491 & 3.83902972 & 2.731385505 & -3.240478706 & $\begin{array}{l}\text { DREB protein } \\
1 \mathrm{~A}\end{array}$ \\
\hline Solyc04g071770.3 & AP2 & 1.046931654 & 4.148131752 & 1.415439268 & -1.685760831 & ABR1-like \\
\hline Solyc01g108240.3 & AP2 & -2.985011238 & 6.732941547 & 4.101471562 & -5.616481223 & ERF109 \\
\hline Solyc12g088390.1 & $\mathrm{C} 2 \mathrm{H} 2$ & -1.773507133 & -1.046854742 & -1.473437274 & -2.200089665 & $\begin{array}{l}\text { zinc finger } \\
\text { protein ZAT10- } \\
\text { like }\end{array}$ \\
\hline Solyc11g073075.1 & $\mathrm{C} 2 \mathrm{H} 2$ & -1.494180824 & 1.227689588 & -1.300679996 & -4.022550408 & $\begin{array}{l}\text { zinc finger } \\
\text { protein ZAT11- } \\
\text { like }\end{array}$ \\
\hline Solyc06g075780.3 & $\mathrm{C} 2 \mathrm{H} 2$ & -1.007553807 & 2.948485153 & 2.280398011 & -1.675640949 & $\begin{array}{l}\text { zinc finger } \\
\text { protein ZAT1- } \\
\text { like }\end{array}$ \\
\hline Solyc07g062710.4 & bZIP & -1.685218283 & -1.945768617 & -2.267994922 & -2.007444587 & $\begin{array}{l}\text { basic leucine } \\
\text { zipper } 61 \text {-like }\end{array}$ \\
\hline
\end{tabular}

Real-time RT-PCR (RT-qPCR) verification of DEGs 
To validate RNA-Seq data, 14 genes were chosen for real-time RT-PCR (RT-qPCR) analysis (Fig. 6). The selected genes comprised eight phytohormone-related and six transcription factors-related genes. The phytohormone-related genes were namely five Eth-related signaling pathway genes (Solyc01g095140, Solyc01g108240, Solyc04g071770, Solyc06g035700 and Solyc10g050970), two IAArelated signaling pathway genes (Solyc09g008175 and Solyc11g069093), and one ABA-related signaling pathway gene (Solyc05g024260). The transcription factor-related genes consisted of one bHLH- (Solyc03g 114230), one AP2- (Solyc03g124110), two C2H2- (Solyc06g075780 and Solyc12g088390), one bZip- (Solyc07g062710) and one MYB-related gene (Solyc02g085145). The RTqPCR results were broadly consistent with the RNA-Seq data for the majority of the tested genes. For example, in both RNA-Seq and RTqPCR data, Solyc01g095140 had the highest and lowest expression in TM0 (+ PEG6000/-melatonin) and CM10 (PEG6000/+melatonin) plants, respectively.

\section{Discussion}

Tomato (Solanum lycopersicum L.) is widely cultivated all over the world as one of the most important horticultural crops. However, tomato plants are highly susceptible to water deficit, not only during the vegetative growth phase but particularly during the stages of flowering and the fruit set. Water deficiency seriously damages leaf and fruit size, fruit number, photosynthetic rate and fruit quality [40, 41]. Melatonin is a pleiotropic signaling molecule; in addition to promoting ripening and improving the quality of tomato fruit postharvest, it also provides physiological protection for plants against various abiotic stresses [19]. Researchers found that exogenous melatonin application improves tolerance to water deficit by promoting cuticle formation in tomato plants [33]. In the current study, the mechanism by which melatonin alleviated drought damage in tomato plants was investigated from the perspective of photosynthetic protection and differentially gene expression induced by melatonin application.

Tomato plant height decreased significantly after simulation of drought stress by continuous PEG6000 treatment, which indicated that drought delayed the growth rate of tomato plants (Fig. 1). These results were also consistent with those from a previous study with a different tomato cultivar, Jing fen 2, which found that, relative to plants grown with drought stress, plant height under mild stress, moderate stress or severe stress decreased by $11.49 \%, 28.6 \%$ or $43.98 \%$, respectively [42]. Another recent study showed that water deficit was associated with significant inhibition of growth of tobacco seedlings, decreasing the biomass of shoots and roots, and that melatonin application could alleviate drought stress-induced growth inhibition [43]. In the present study, relative to plants grown without melatonin application, tomato plant height increase ratio was enhanced from day 5 to day 7 after irrigation with melatonin (Fig. 1B).

Plants growing under drought conditions face many challenges at both the biochemical and molecular levels, which eventually hinder the growth and yield of plants $[44,45]$. The plant photosynthetic apparatus will be destroyed under drought stress, resulting in decreases in photosynthetic rate, stomatal conductance, transpiration rate, PSII photochemical efficiency and photosynthetic electron transfer rate. However, melatonin prevents the photosynthetic mechanism from being damaged by drought, and then restores the photosynthetic efficiency of plants [46]. In the current study, decreased levels of Fv/Fm, Fv'/Fm', ETR and qP caused by drought stress were largely recovered following melatonin treatment (Fig. 2). These results were consistent with those from the previous study where the recovered photosynthetic rate as a result of melatonin treatment of droughted plants was accompanied by improved Fv/Fm and ETR values [46].

Pairwise comparisons were performed in four groups of CM10-vs-CM0, TM0-vs- CM0, TM10-vs-CM10 and TM10-vs-TM0. Numbers of DEGs and Venn diagram analysis are illustrated in Fig. 3. The comparative group of TM10-vs-CM10 contained the largest number of DEGs. Also, compared with the group of TMO-vs-CMO which contained much more up-regulated DEGs, the number of up-regulated DEGs was only slightly higher than that of down-regulated DEGs in the group of TM10-vs-CM10 (Fig. 3). These results hinted that melatonin treatment increased both the number of total DEGs and down-regulated DEGs. Similarly, Debnath et al. (2020) showed that exogenous melatonin application protected tomato seedlings from acid rain stress by changing the expression patterns of DEGs, principally secondary metabolites and transcription factor-related genes [47]. Function annotation of DEGs were often performed with GO or KEGG analysis [38, 48]. In this study, DEGs from the four groups were classified with GO and KEGG database (Figs. 4 and 5).

Phytohormones and transcription factors play critical roles in the response of plants to drought stress. In the current study, DEGs involved in different hormone signaling pathways were identified from the four groups (Tables S5, S6, S7 and S8). For instance, ethylene is a hormone closely related to the processes of maturity, senescence and stress response. Ethylene-responsive factors (ERFs, belonging to the AP2/ERF family) are widely involved in the regulation of gene expression in response to external environmental stresses in plants. For example, the expression of ERFs increased under drought stress to achieve increased stress tolerance [49]. In

Page 8/18 
tomato, ER5 and ERF5 have been shown to function in promoting adaptation to drought stress in tomato [50,51]. In the current study, five ethylene-related DEGs, which were common to the four comparative groups (CM10-vs-CM0, TM0-vs-CM0, TM10-vs-CM10 and TM10-vs-TM0), contained ER5 (Solyc01g095140) and four ERF genes (Solyc06g035700, Solyc10g050970, Solyc04g071770 and Solyc01g108240) (Tables 1 and 2). The expression of these genes was up-regulated by drought, whereas, interestingly, melatonin irrigation reduced the up regulatory effect of these genes in response to drought (Table 1, Fig. 6). Similar results were observed during melon root development; compared with the group of melon roots exposed to copper stress, the expression of the AP2/ERF gene in the melatonin pre-treatment group was down regulated and the authors speculated that melatonin may alleviate copper stress and promote melon root development by reducing the expression of the AP2/ERF gene [52].

Auxin regulates the expression of hundreds of genes, such as members of the early auxin response gene family, Aux/IAA, Gretchen Hagen3 (GH3) and Small Auxin-Up RNA (SAUR) [53]. In the present study, two IAA-related genes, Solyc09g008175 (SAUR71) and Solyc11g069093 (auxin-induced protein X15), which were common to the four groups, showed similar expression patterns (Table 1 , Fig. 6). The expression of these two genes was suppressed under PEG6000 treatment, whereas melatonin treatment further enhanced the down-regulation effect on gene expression (Fig. 6). Similar results were reported in a previous study which revealed that the SAUR gene family contained 99 members and that the expression of many SAUR genes, including SAUR71, was down-regulated under drought treatments [54]. High levels of endogenous SA and the application of exogenous SA can promote stomatal closure and induce reduced photosynthesis rate during water deficit to conserve water [55]. The Solyc05g024260 gene is related to both SA and ABA signal transduction and is shared by the four groups (Table 1). The expression of Solyc05g024260 was up-regulated by drought, whereas melatonin irrigation reduced the drought-induced up-regulatory effect (Table 1, Fig. 6).

In the current study, DEGs associated with different types of transcription factors (TFs) were identified from the four groups (Tables S9, $\mathrm{S} 10, \mathrm{~S} 11$ and S12). A previous study had reported that expression of a gene named $I b Z F P 1$, encoding a $\mathrm{C} 2 \mathrm{H} 2 \mathrm{TF}$, could be induced by PEG treatment in sweet potato [56]. $\mathrm{C} 2 \mathrm{H} 2$ zinc-finger proteins regulate plant responses to drought stress through ABA-dependent and ABA-independent pathways [57]. In the present study, three different C2H2 gene family members (Solyc12g088390, Solyc11g073075 and Solyc06g075780) were shared by the four DEG groups (Table 1). The expression of Solyc06g075780, but not that of Solyc12g088390, was induced by PEG6000 treatment, but the expression of both genes could be down-regulated by melatonin treatment (Fig. 6). Mitogen-activated protein kinase (MAPK) cascade pathways play a crucial role in regulating the biological processes of plants exposed to abiotic stresses, such as drought [58]. The expression pattern of MAPKs showed up-regulation by melatonin under drought stress, accompanied by the up-regulation of expression of several families of TFs, such as WRKY, DREB and MYB, which are the main components of the MAPK signaling pathway in plants under stress conditions $[58,59]$. Recent research has shown that melatonin changes the expression of many transcription factor genes and secondary metabolite genes in tomato to improve the plant's tolerance to acid rain stress [47]. In the present study, different types of transcription factors were found among the DEGs (Table 2, Fig. 6).

In brief, melatonin was involved in improving plant stress tolerance and growth under drought stress conditions. In the present study, in combination with the analysis of several physiological parameters (Fv/Fm, Fv'/Fm', ETR, qP, qN and NPQ), RNA-Seq technology was used to investigate the effect of response to melatonin irrigation under non-drought and drought conditions. The analysis of plant phenotype, physiological parameters and DEGs provides a firm foundation to the physiological and molecular mechanisms of the role of melatonin in improving tomato drought stress tolerance.

\section{Declarations}

Acknowledgements The study was funded by the 17th Huo Yingdong Education Fund Project (171022), Anhui Provincial Natural Science Foundation (2008085QC129, 2008085MC77), and the Provincial Natural Science Research Program of Higher Education of Anhui province (KJ2019A0484).

\section{Declarations}

Conflict of Interest The authors declare no conflicts of interest.

Ethical Approval This article does not contain any studies with human participants or animals performed by any of the authors.

\section{References}


1. James D, Borphukan B, Fartyal D, Ram B, Singh J, Manna M et al (2018) Concurrent overexpression of OsGS1;1 and OsGS2 genes in transgenic rice (Oryza sativa I.): impact on tolerance to abiotic stresses. Front Plant Sci 9:786.

https://doi.org/10.3389/fpls.2018.00786

2. Conti V, Mareri L, Faleri C, Nepi M, Romi M, Cai G et al (2019) Drought stress affects the response of italian local tomato (Solanum lycopersicum L.) varieties in a genotype-dependent manner. Plants 8(9):336. https://doi.org/10.3390/plants8090336

3. Joshi R, Wani SH, Singh B, Bohra A, Dar ZA, Lone AA et al (2016) Transcription factors and plants response to drought stress: Current understanding and future directions. Front Plant Sci 7:1029. https://doi.org/10.3389/fpls.2016.01029

4. Xu L, Naylor D, Dong ZB, Simmons T, Pierroz G, Hixson KK et al (2018) Drought delays development of the sorghum root microbiome and enriches for monoderm bacteria. Proc Natl Acad Sci U S A 115(18):E4284-E4293.

https://doi.org/10.1073/pnas.1717308115

5. Wang SQ, Zhang X, Chen NC (2020) Applicability analysis of three compound drought indexes in three major agricultural production areas in China. Agric Res Arid Areas 38(1):243-254

6. Matsukura C, Aoki K, Fukuda N, Mizoguchi T, Asamizu E, Saito T et al (2008) Comprehensive resources for tomato functional genomics based on the miniature model tomato Micro-Tom. Curr Genom 9(7):436-443.

https://doi.org/10.2174/138920208786241225

7. Bartels D, Sunkar R (2005) Drought and salt tolerance in plants. Crit Rev Plant Sci 24:23-58. https://doi.org/10.1080/07352680590910410

8. Nuruddin MM, Madramootoo CA, Dodds GT (2003) Effects of water stress at different growth stages on greenhouse tomato yield and quality. HortScience 38:1389-1393. https://doi.org/10.21273/HORTSCI.38.7.1389

9. Bray EA (1990) Drought-stress-induced polypeptide accumulation in tomato leaves. Plant Cell Environ 13(6):531-538. https://doi.org/10.1111/j.1365-3040.1990.tb01069.x

10. Pervez MA, Ayub CM, Khan HA, Shahid MA, Ashraf I et al (2009) Effect of drought stress on growth, yield and seed quality of tomato (Lycopersicon esculentum L.). Pak J Agric Sci 46:174-178

11. Sivakumar R, Srividhya S (2016) Impact of drought on flowering, yield and quality parameters in diverse genotypes of tomato (Solanum lycopersicum L.). Adv Hortic Sci 30(1):3-12. https://doi.org/10.13128/ahs-18696

12. Sun ZG (2014) Physiological response for PEG-6000 simulation naked fruit tree seedlings under drought stress. Gansu Agricultural Science Technology 12:41-44

13. Arnao MB, Hernández-Ruiz J (2018) Melatonin and its relationship to plant hormones. Ann Bot 121:195-207. https://doi.org/10.1093/aob/mcx114

14. Wang P, Sun X, Li C, Wei ZW, Liang D, Ma FW (2013) Long-term exogenous application of melatonin delays drought-induced leaf senescence in apple. J Pineal Res 54(3):292-302. https://doi.org/10.1111/jpi.12017

15. Zhang N, Zhao B, Zhang HJ, Weeda S, Yang C, Yang ZC et al (2013) Melatonin promotes water-stress tolerance, lateral root formation, and seed germination in cucumber (Cucumis sativus L.). J Pineal Res 54(1):15--23. https://doi.org/10.1111/j.1600079X.2012.01015.x

16. Alam MN, Zhang LH, Yang L, Islam MR, Liu Y, Luo H et al (2018) Transcriptomic profiling of tall fescue in response to heat stress and improved thermotolerance by melatonin and 24-epibrassinolide. BMC Genom 19:224. https://doi.org/10.1186/s12864-0184588-y

17. Byeon Y, Back K (2014) Melatonin synthesis in rice seedlings in vivo is enhanced at high temperatures and under dark conditions due to increased serotonin Nacetyltransferase and N-acetylserotonin methyltransferase activities. J Pineal Res 56:189-195. https://doi.org/10.1111/jpi.12111

18. Shi HT, Tan DX, Reiter RJ, Ye TT, Yang F, Chan ZL et al (2015) Melatonin induces class A1 heat-shock factors (HSFA1s) and their possible involvement of thermotolerance in Arabidopsis. J Pineal Res 58:335-342. https://doi.org/10.1111/jpi.12219

19. Xu W, Cai SY, Zhang Y, Wang Y, Ahammed GJ, Xia XJ et al (2016) Melatonin enhances thermotolerance by promoting cellular protein protection in tomato plants. J Pineal Res 61:457-469. https://doi.org/10.1111/jpi.12359

20. Chen YE, Mao JJ, Sun LQ, Huang B, Ding CB, Gu Y et al (2018) Exogenous melatonin enhances salt stress tolerance in maize seedlings by improving antioxidant and photosynthetic capacity. Physiol Plantarum 164:349-363.

https://doi.org/10.1111/ppl.12737 
21. Fleta-Soriano E, Diaz L, Bonet E, Munné-Bosch S (2017) Melatonin may exert a protective role against drought stress in maize. J Agron Crop Sci 203(4):286-294. https://doi.org/10.1111/jac.12201

22. Bajwa VS, Shukla MR, Sherif SM, Murch SJ, Saxena PK (2014) Role of melatonin in alleviating cold stress in Arabidopsis thaliana. J Pineal Res 56:238-245. https://doi.org/10.1111/jpi.12115

23. Zhao HL, Zhang K, Zhou XT, Xi LJ, Wang YP, Xu HJ et al (2017) Melatonin alleviates chilling stress in cucumber seedlings by upregulation of CsZat12 and modulation of polyamine and abscisic acid metabolism. Sci Rep 7:4998. https://doi.org/10.1038/s41598-017-05267-3

24. Liu CX, Chen LL, Zhao RR, Li R, Zhang SJ, Yu WQ et al (2019) Melatonin induces disease resistance to botrytis cinerea in tomato fruit by activating jasmonic acid signaling pathway. J Agric Food Chem 67(22):6116-6124. https://doi.org/10.1021/acs.jafc.9b00058

25. Arnao MB, Hernández-Ruiz J (2015) Functions of melatonin in plants: a review. JPineal Res 59(2):133-150. https://doi.org/10.1111/jpi.12253

26. Lee HY, Byeon Y, Tan DX, Reiter RJ, Back K (2015) Arabidopsis serotonin N-acetyltransferase knockout mutant plants exhibit decreased melatonin and salicylic acid levels resulting in susceptibility to an avirulent pathogen. J Pineal Res 58(3):291-299. https://doi.org/10.1111/jpi.12214

27. Yin LH, Wang P, Li MJ, Ke XW, Li CY, Liang D et al (2013) Exogenous melatonin improves Malus resistance to Marssonina apple blotch. J Pineal Res 54(4):426-434. https://doi.org/10.1111/jpi.12038

28. Jahan MS, Shu S, Wang Y, Chen Z, He MM, Tao MQ et al (2019) Melatonin alleviates heat-induced damage of tomato seedlings by balancing redox homeostasis and modulating polyamine and nitric oxide biosynthesis. BMC Plant Biol 19(1):414. https://doi.org/10.1186/s12870-019-1992-7

29. Sun QQ, Zhang N, Wang JF, Zhang HJ, Li DB, Shi J et al (2015) Melatonin promotes ripening and improves quality of tomato fruit during postharvest life. J Exp Bot 66(3):657-668. https://doi.org/10.1093/jxb/eru332

30. Wang M, Zhang S, Ding F (2020) Melatonin mitigates chilling-induced oxidative stress and photosynthesis inhibition in tomato plants. Antioxidants 9(3):218. https://doi.org/10.3390/antiox9030218

31. Liu D-D, Sun X-S, Liu L, Shi HD, Chen SY, Zhao DK et al (2019) Overexpression of the melatonin synthesis-related gene slcomt1 improves the resistance of tomato to salt stress. Molecules 24(8):1514. https://doi.org/10.3390/molecules24081514

32. Liu JL, Wang WX, Wang LY, Sun Y (2015) Exogenous melatonin improves seedling health index and drought tolerance in tomato. Plant Growth Regul 77(3):317-326. https://doi.org/10.1007/s10725-015-0066-6

33. Ding F, Wang G, Wang ML, Zhang SX (2018) Exogenous melatonin improves tolerance to water deficit by promoting cuticle formation in tomato plants. Molecules 23(7):1605. https://doi.org/10.3390/molecules23071605

34. Karaca P, Cekic F (2019) Exogenous melatonin-stimulated defense responses in tomato plants treated with polyethylene glycol. J Veg Sci 25(6):601-609. https://doi.org/10.1080/19315260.2019.1575317

35. Ibrahim MFM, Elbar OHA, Farag R, Hikal M, El-Kelish A, El-Yazied AA et al (2020) Melatonin counteracts drought induced oxidative damage and stimulates growth, productivity and fruit quality properties of tomato plants. Plants 9(10):1276. https://doi.org/10.3390/plants9101276

36. Bilger W, Björkman O (1991) Temperature-dependence of violaxanthin deepoxidation and nonphotochemical fluorescence quenching in intact leaves of Gossypium hirsutum L. and Malva parviflora L. Planta 184:226-234. https://doi.org/10.1007/BF00197951

37. Borek M, Baczek-kwinta R, Rapacz M (2016) Photosynthetic activity of variegated leaves of Coleus x hybridus hort. cultivars characterised by chlorophyll fluorescence techniques. Photosynthetica 54(3):331-339. https://doi.org/10.1007/s11099-016-02257

38. Yang L, Li QQ, Yang Y, Chen Q, Gao X, Xiao XJ (2020) Comparative transcriptome analysis reveals positive effects of arbuscular mycorrhizal fungi inoculation on photosynthesis and high-ph tolerance in blueberry seedlings. Trees 34(2):433-444. https://doi.org/10.1007/s00468-019-01926-2

39. Wang LK, Feng ZX, Wang X, Wang XW, Zhang XG (2010) DEGseq: an R package for identifying differentially expressed genes from RNA-seq data. Bioinformatics 26(1):136-138. https://doi.org/10.1093/bioinformatics/btp612

40. Dodds GT, Trenholm L, Rajabipour A, Madramootoo CA, Norris ER (1997) Yield and quality of tomato fruit under water-table management. J Am Soc Hortic Sci 122:491-498. https://doi.org/10.21273/JASHS.122.4.491

Page 11/18 
41. Murshed R, Lopez-Lauri F, Sallanon H (2013) Effect of water stress on antioxidant systems and oxidative parameters in fruits of tomato (Solanum lycopersicon L, cv. Micro-tom). Physiol Mol Biol Plants 19:363-378. https://doi.org/10.1007/s12298-013-01737

42. Yang ZQ, Qiu YX, Liu ZX, Chen YQ, Tan W (2016) The effects of soil moisture stress on the growth of root and above-ground parts of greenhouse tomato crops. Acta Ecol Sin 36(3):748-757

43. Liu L, Li D, Ma YL, Shen HT, Zhao SM, Wang YF (2020) Combined application of arbuscular mycorrhizal fungi and exogenous melatonin alleviates drought stress and improves plant growth in tobacco seedlings. J Plant Growth Regul 40:1074-1087. https://doi.org/10.1007/s00344-020-10165-6

44. Ahmad Z, Anjum S, Waraich EA, Ayub MA, Ahmad T, Tariq RMS et al (2018) Growth, physiology, and biochemical activities of plant responses with foliar potassium application under drought stress-A review. J Plant Nutr 41(13):1734-1743. https://doi.org/10.1080/01904167.2018.1459688

45. Hussain HA, Hussain S, Khaliq A, Ashraf U, Anjum SA, Men SN et al (2018) Chilling and Drought Stresses in Crop Plants: Implications, cross Talk, and Potential Management Opportunities. Front Plant Sci 9:393. https://doi.org/10.3389/fpls.2018.00393

46. Liang BW, Ma CQ, Zhang ZJ, Wei ZW, Gao TT, Zhao Q (2018) Long-term exogenous application of melatonin improves nutrient uptake fluxes in apple plants under moderate drought stress. Environ Exp Bot 155:650-661. https://doi.org/10.1016/j.envexpbot.2018.08.016

47. Debnath B, Li M, Liu S, Pan TF, Ma CL, Qiu DL (2020) Melatonin-mediate acid rain stress tolerance mechanism through alteration of transcriptional factors and secondary metabolites gene expression in tomato. Ecotoxicol Environ Saf 200:110720. https://doi.org/10.1016/j.ecoenv.2020.110720

48. Zhou ZX, Liu HC, Ma CN, Chao YH, Han LB (2020) Transcriptome analysis of the cytokinin response in medicago truncatula. Journal of Plant Biology, 63(7). https://doi.org/10.1007/s12374-020-09244-8

49. Govind G, Harshavardhan VT, Hong CY (2020) Phytohormone Signaling in Response to Drought. Salt and Drought Stress Tolerance in Plants: pp 315-335. https://doi.org/10.1007/978-3-030-40277-8_12

50. Pan Y, Seymour GB, Lu CG, Hu ZL, Chen XQ, Chen GP (2012) An ethylene response factor (ERF5) promoting adaptation to drought and salt tolerance in tomato. Plant Cell Rep 31(2):349-360. https://doi.org/10.1007/s00299-011-1170-3

51. Zegzouti H, Jones B, Marty C, Lelièvre JM, Latché A, Pech JC et al (1997) Er5, a tomato cDNA encoding an ethylene-responsive LEA-like protein: characterization and expression in response to drought, ABA and wounding. Plant Mol Biol 35(6):847-854. https://doi.org/10.1023/A:1005860302313

52. Hu ZC, Fu QS, Zheng J, Zhang AA, Wang HS (2020) Transcriptomic and metabolomic analyses reveal that melatonin promotes melon root development under copper stress by inhibiting jasmonic acid biosynthesis. Hortic Res 7:79. https://doi.org/10.1038/s41438-020-0293-5

53. Nemhauser JL, Hong F-X, Chory J (2006) Different plant hormones regulate similar processes through largely nonoverlapping transcriptional responses. Cell 126:467-475. https://doi.org/10.1016/j.cell.2006.05.050

54. Jian W, Liu S, He Y, Guan XY, Zhu XF, Cheng L et al (2012) Genome-wide analysis of SAUR gene family in solanaceae species. Gene 509(1):38-50. https://doi.org/10.1016/j.gene.2012.08.002

55. Korkmaz A, Uzunlu M, Demirkiran AR (2007) Treatment with acetyl salicylic acid protects muskmelon seedlings against drought stress. Acta Physiol Plant 29:503-508. https://doi.org/10.1007/s11738-007-0060-3

56. Liu QG, Wang ZC, Xu XM, Zhang HZ, Li CH (2015) Genome-Wide Analysis of C2H2 Zinc-Finger Family Transcription Factors and Their Responses to Abiotic Stresses in Poplar (Populus trichocarpa). Plos One 10(8):e0134753.

https://doi.org/10.1371/journal.pone.0134753

57. Wang K, Ding YF, Cai C, Chen ZX, Zhu C (2019) The role of c2h2 zinc finger proteins in plant responses to abiotic stresses. Physiol Plant 165(4):690-700. https://doi.org/10.1111/ppl.12728

58. Zhang L, Xi DM, Li SW, Gao Z, Zhao SL, Shi J et al (2011) A cotton group C MAP kinase gene, GhMPK2, positively regulates salt and drought tolerance in tobacco. Plant Mol Biol 77(1-2):17-31. https://doi.org/10.1007/s11103-011-9788-7

59. Gao WY, Zhang YJ, Feng Z, Bai QQ, He JJ, Wang YJ et al (2018) Effects of Melatonin on Antioxidant Capacity in Naked Oat Seedlings under Drought Stress. Molecules 23(7):1580. https://doi.org/10.3390/molecules23071580

\section{Figures}

Page 12/18 


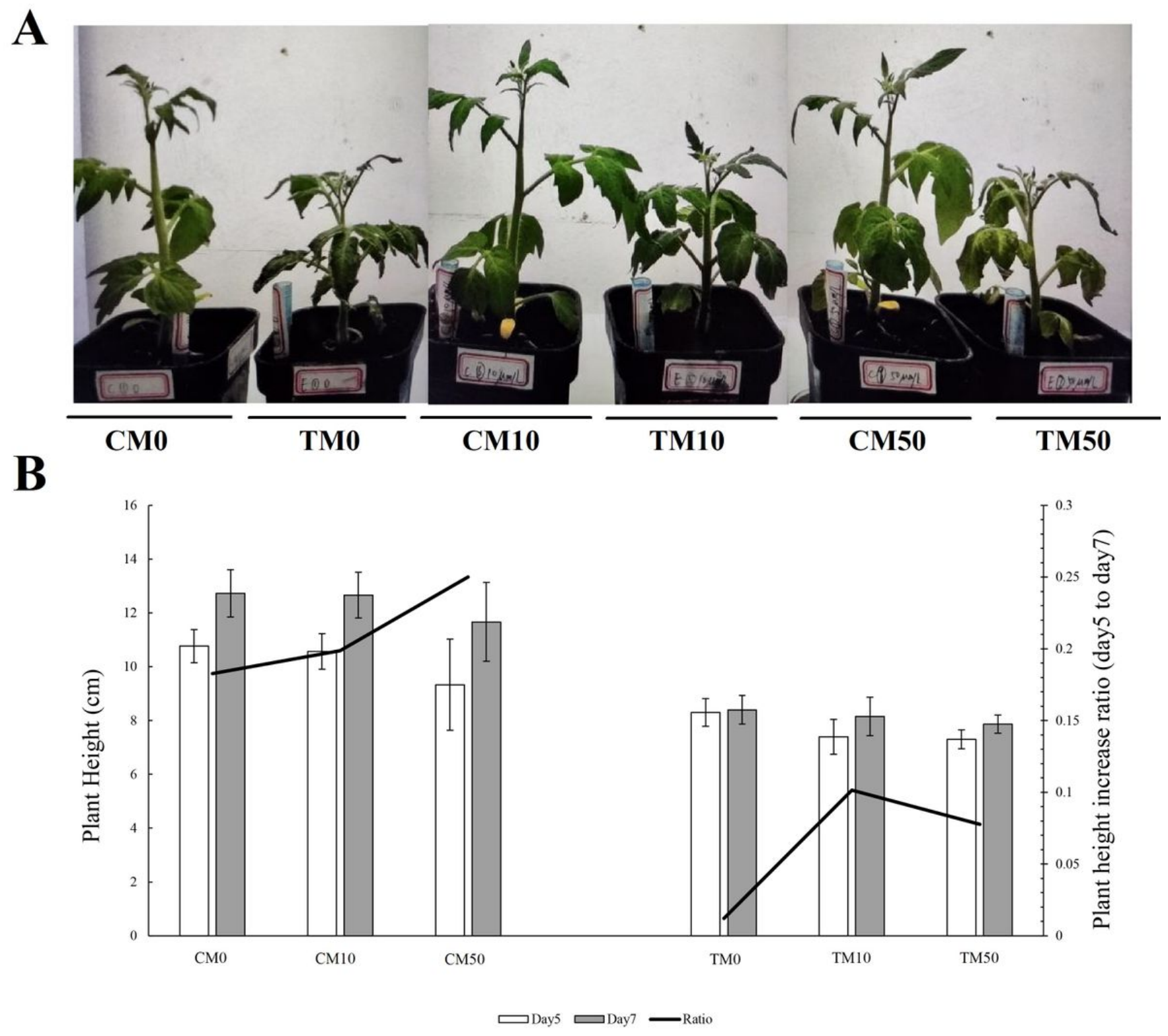

\section{Figure 1}

Melatonin alleviates tomato plant damage induced by PEG6000 simulated drought treatment. A. Growth state of tomato plants after combined application of different concentrations of melatonin $(0,10,50 \mu \mathrm{mol} / \mathrm{L})$ under normal and PEG6000 simulated drought conditions. CM0, melatonin was not applied under normal condition; TM0, melatonin was not applied under PEG6000 simulated drought condition; CM10, $10 \mu \mathrm{mol} / \mathrm{L}$ melatonin was applied under normal condition; TM10, $10 \mu \mathrm{mol} / \mathrm{L}$ melatonin was applied under PEG6000 simulated drought condition; CM50, $50 \mu \mathrm{mol} / \mathrm{L}$ melatonin was applied under normal condition; TM50, $50 \mu \mathrm{mol} / \mathrm{L}$ melatonin was applied under PEG6000 simulated drought condition. B. Plant height and plant height increase ratio (day 5 to day 7) were measured on the fifth and seventh days after treatment. Data represent mean values \pm SD and are derived from at least three plants. 

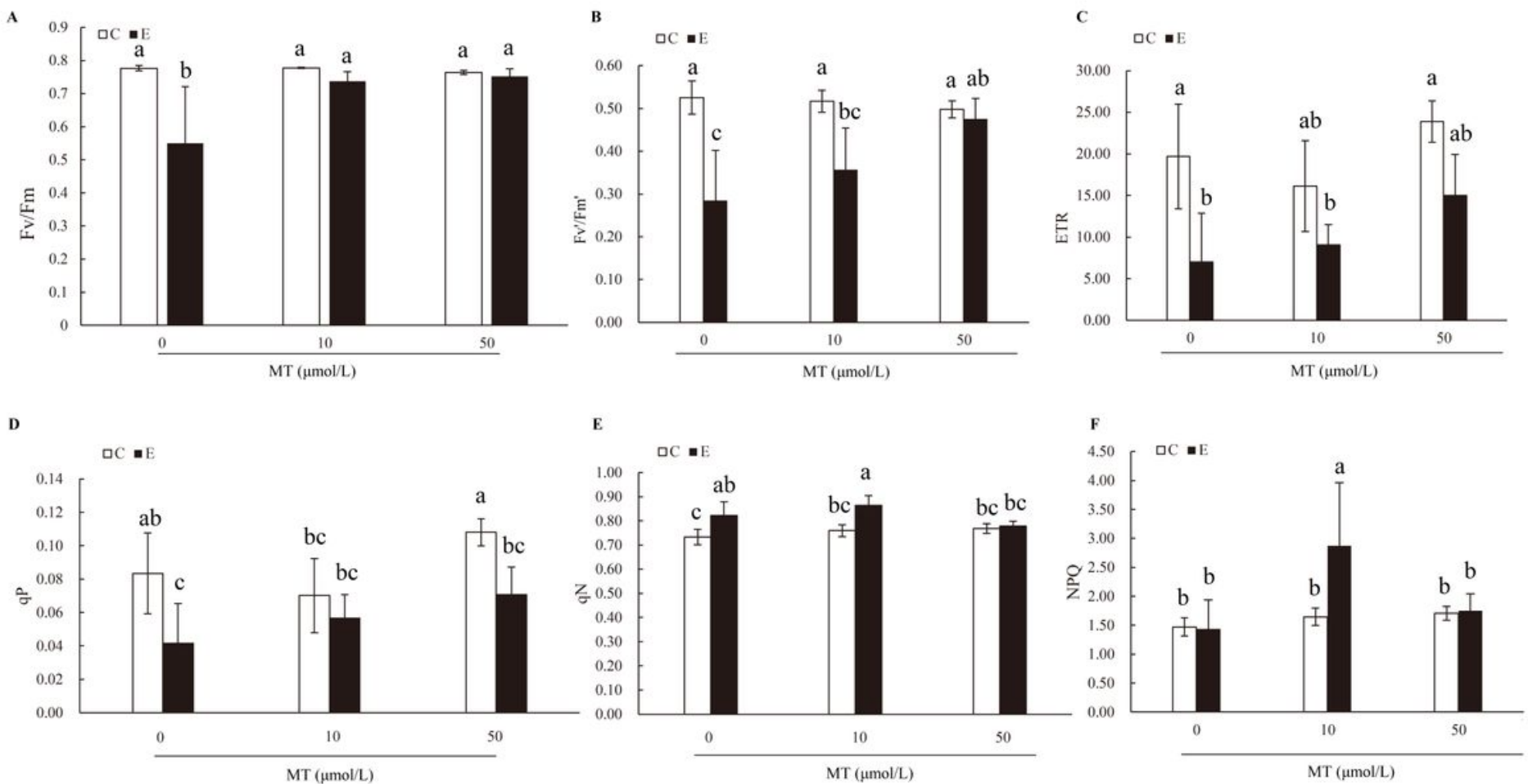

Figure 2

Melatonin alleviated the photosynthetic damage of tomato leaves under PEG6000 simulated drought treatment. Maximum photochemistry efficiency of photosystem (PS) II (Fv/Fm) (A), effective quantum yield of PSIl photochemistry (Fv'/Fm') (B), electron transfer rate (ETR) (C), photochemical quenching (qP) (D), non-photochemical quenching coefficient (qN) (E), and non-photochemical quenching (NPQ) (F) of tomato leaves after combined application of different concentrations of melatonin $(0,10,50 \mu \mathrm{mol} / \mathrm{L}) \mathrm{under}$ normal and PEG6000 simulated drought. The experiments were repeated three times for each and the statistical data are presented as the mean \pm standard deviation. Differences were compared by Duncan's test with a significance level of $p<0.05$. 

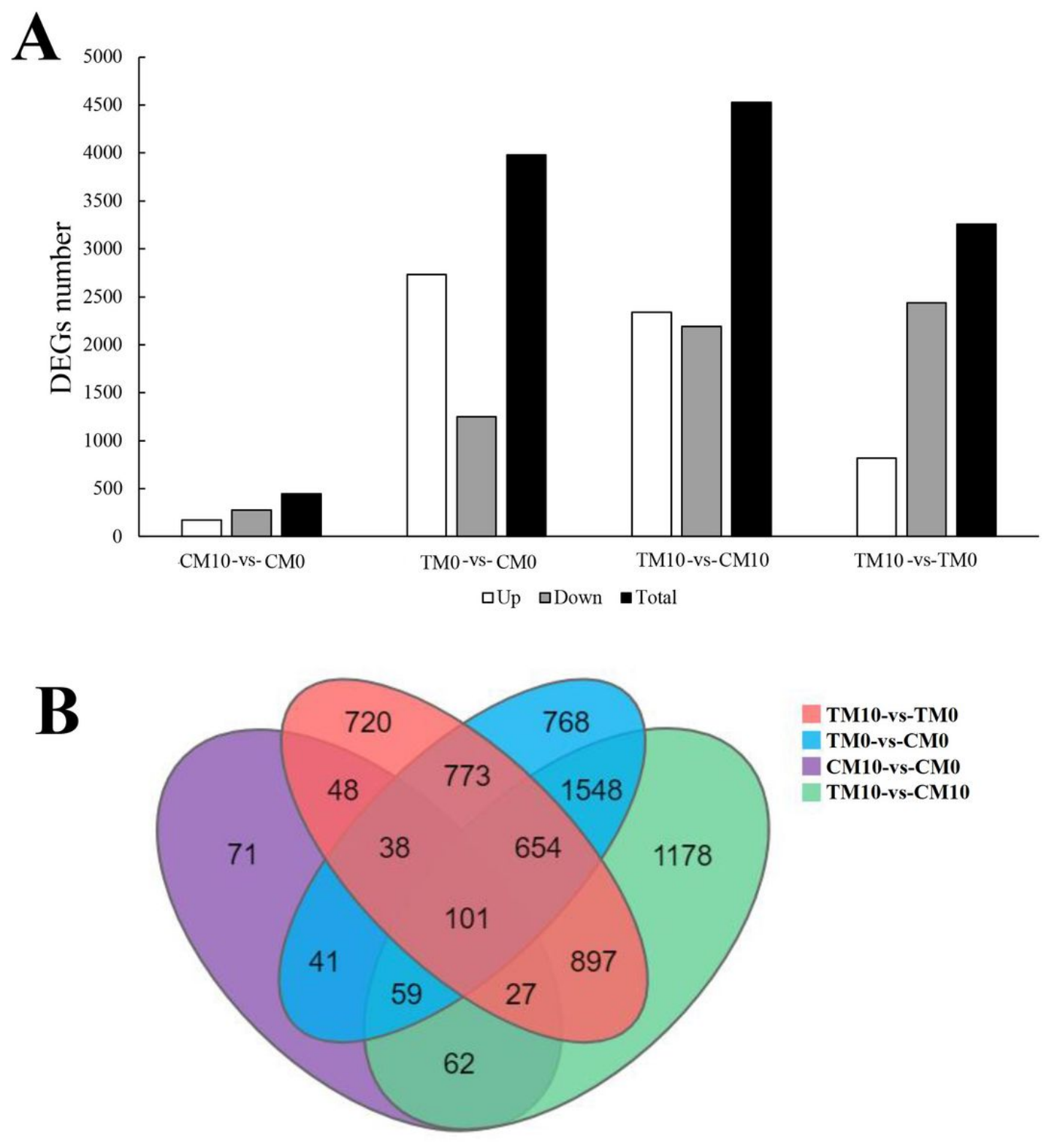

\section{Figure 3}

The number of DEGs in the four comparison groups (CM10-vs-CM0, TM0-vs-CM0, TM10-vs-CM10, TM10-vs-TM0) and Venn diagram analysis. A. The total DEGs number and DEGs numbers of up-regulated as well as down-regulated genes in the four groups. B. Venn diagram analysis of the DEGs numbers in the four groups. 
A

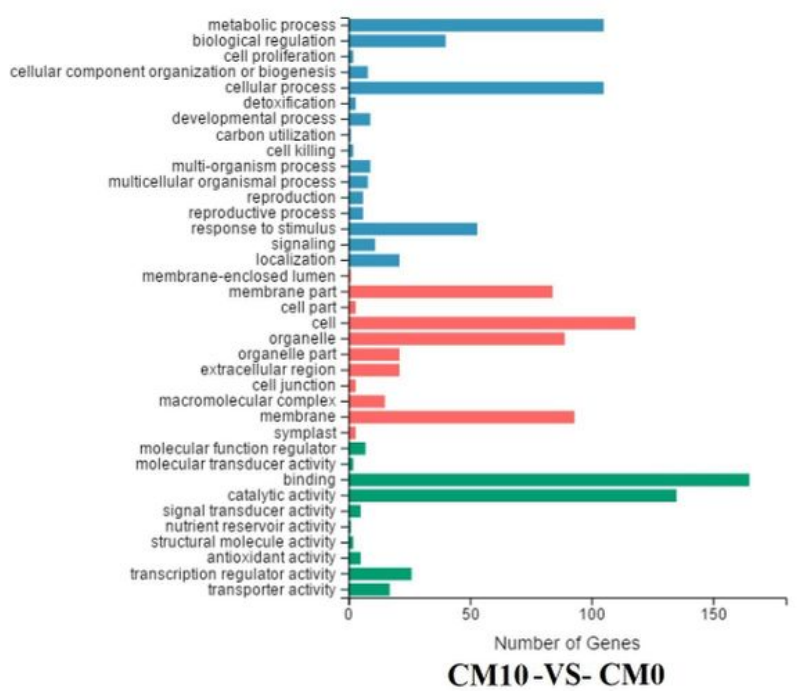

C

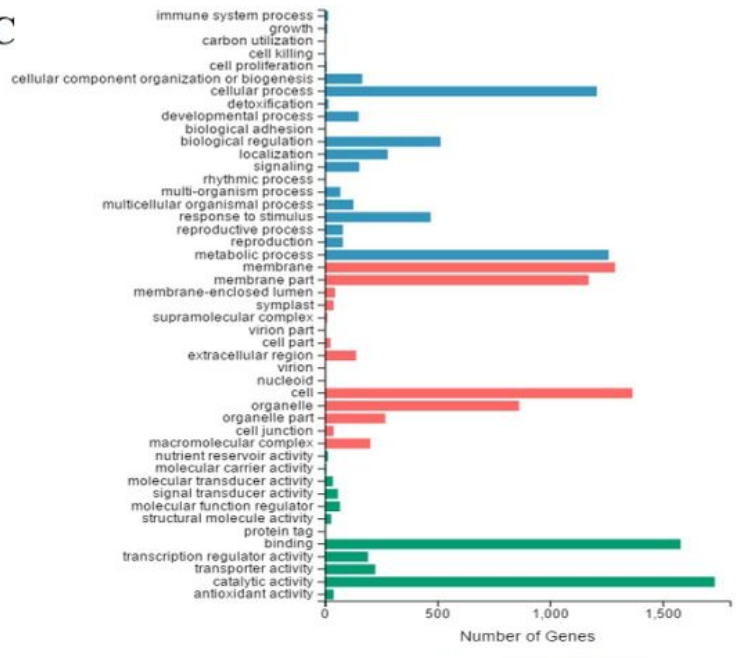

TM10-VS- CM10

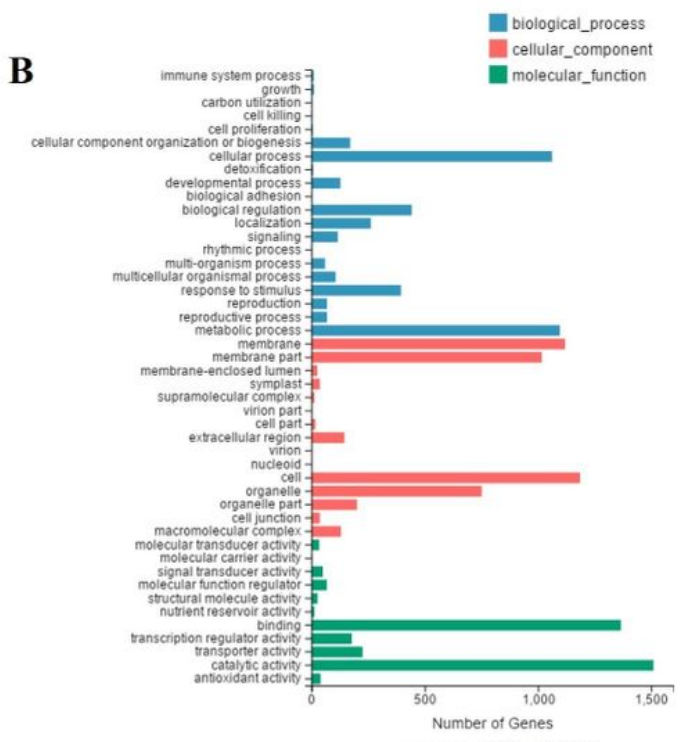

TM0-VS-CM0

D

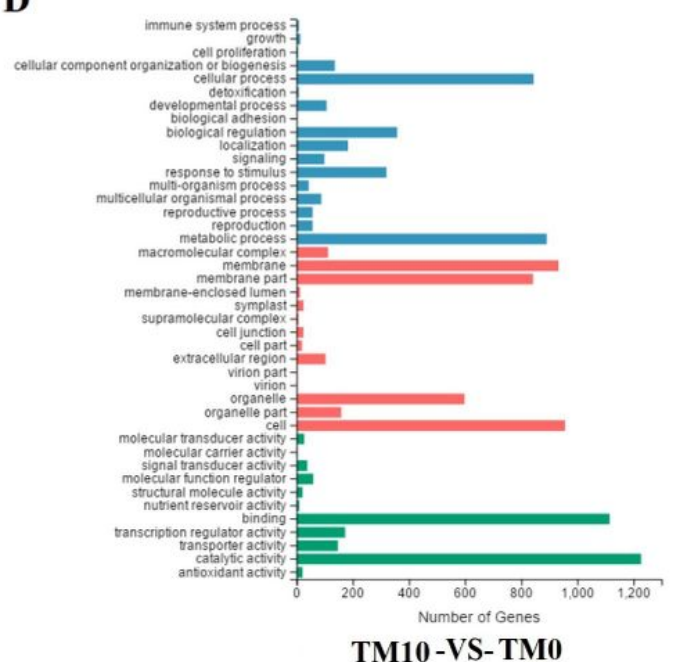

\section{Figure 4}

Function annotation of DEGs in the four comparison groups (CM10-vs-CM0, TM0-vs-CM0, TM10-vs-CM10, TM10-vs-TM0) by Gene Ontology (GO) analysis. A. GO analysis of DEGs in the comparison group of CM10-vs-CMO. B. GO analysis of DEGs in the comparison group of TM0-vs-CM0. C. GO analysis of DEGs in the comparison group of TM10-vs-CM10. D. GO analysis of DEGs in the comparison group of TM10-vs-TM0. 


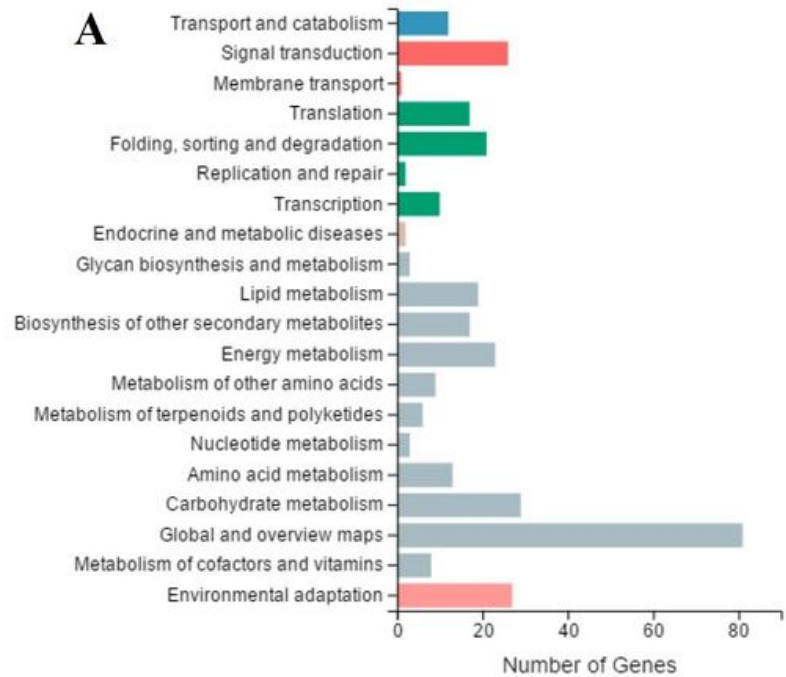

CM10-VS-CM0



TM10-VS-CM10



TM0-VS-CMO

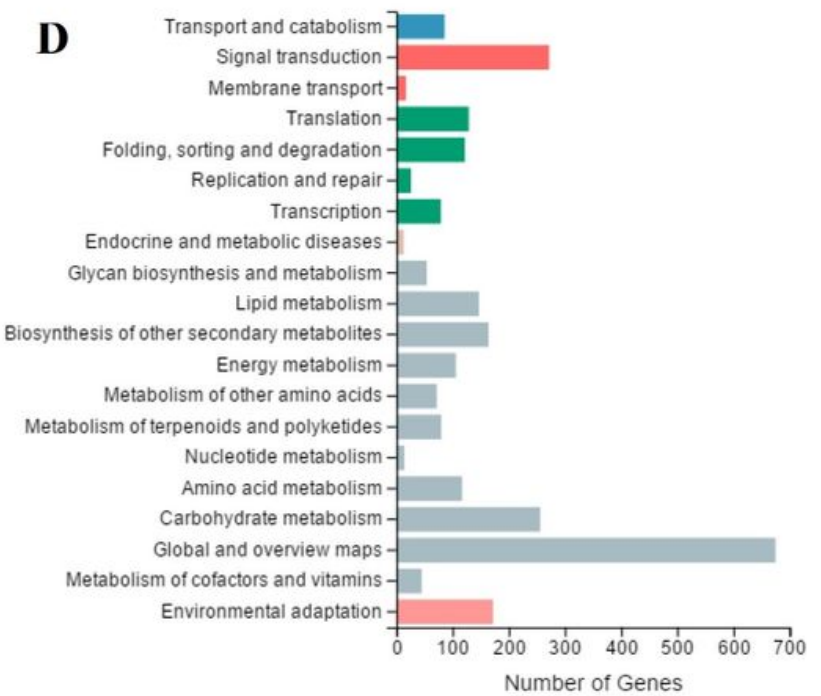

TM10-VS-TM0

\section{Figure 5}

Function annotation of DEGs in the four groups (CM10-vs-CM0, TM0-vs-CM0, TM10-vs-CM10, TM10-vs-TM0) by Kyoto Encyclopedia of Genes and Genomes (KEGG) analysis. A. KEGG analysis of DEGs in the comparison group of CM10-vs-CM0. B. KEGG analysis of DEGs in the comparison group of TM0-vs-CM0. C. KEGG analysis of DEGs in the comparison group of TM10-vs-CM10. D. KEGG analysis of DEGs in the comparison group of TM10-vs-TM0. 
A
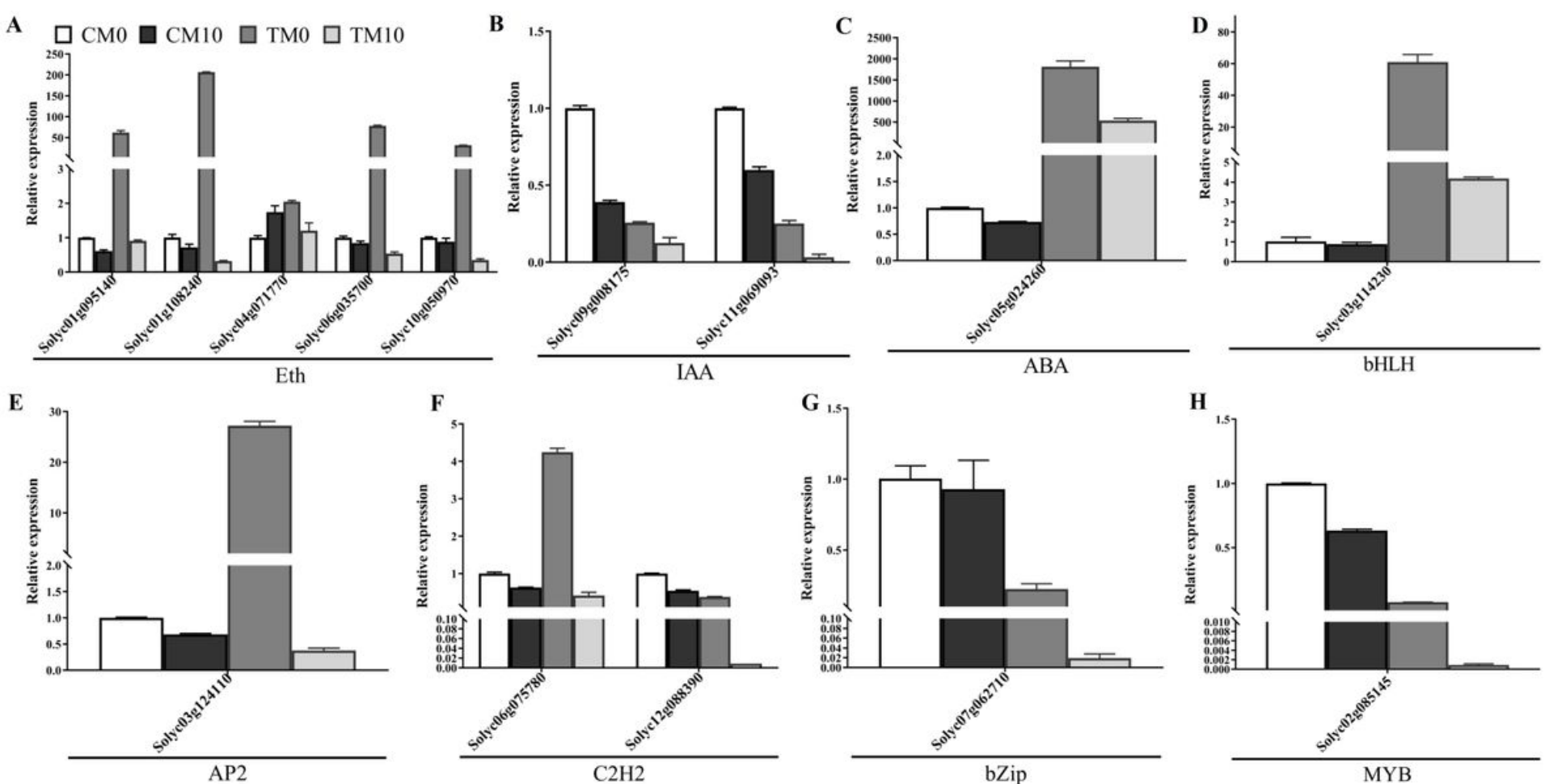

\begin{abstract}
F
\end{abstract}

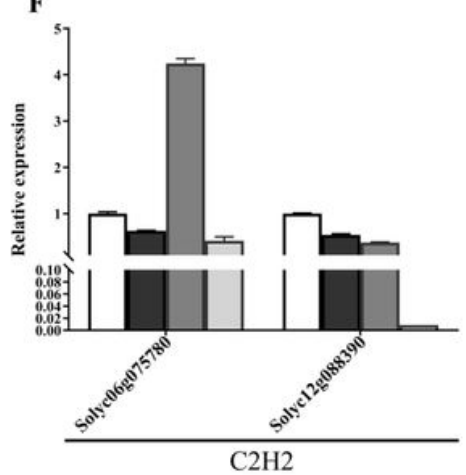



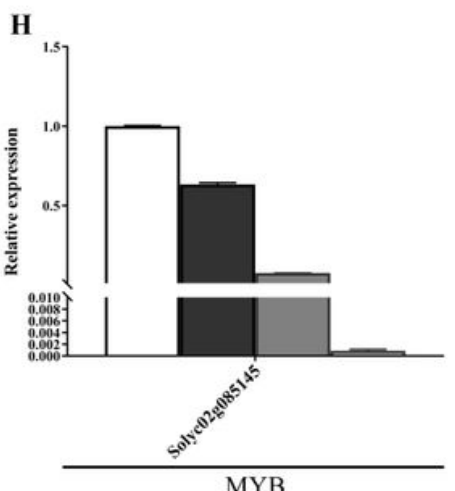

Figure 6

Verification of phytohormones and transcription factor related DEGs by RT-qPCR combined application of different concentrations of melatonin $(0,10 \mu \mathrm{mol} / \mathrm{L})$ under normal and PEG6000 simulated drought. A. Relative expression of five genes related to Eth. B. Relative expression of two genes related to IAA. C. Relative expression of gene related to ABA. D. Relative expression of gene related to bHLH. E. Relative expression of gene related to AP2. F. Relative expression of two genes related to $\mathrm{C} 2 \mathrm{H} 2$. G. Relative expression of gene related to bZip. C. Relative expression of gene related to MYB. Error bars show the standard error between three biological replicates performed $(n=3)$.

\section{Supplementary Files}

This is a list of supplementary files associated with this preprint. Click to download.

- SUPPLEMENTARYMATERIAL.rar 